\title{
Two pathways, one patient; UK asthma guidelines
}

\author{
Stephen J Fowler, ${ }_{1}^{1}$ Paul M O'Byrne, ${ }^{2}$ Roland Buhl, ${ }^{3}$ Dominick Shaw ${ }^{4}$
}

The first widely disseminated 'asthma guideline' came out of Australia and New Zealand in $1989,{ }^{1}$ followed shortly by the British Thoracic Society (BTS) in 1990, ${ }^{2}$ the United States National Heart, Lung, and Blood Institute Expert Panel Report in $1991^{3}$ and the Global Initiative for Asthma (GINA) strategy document in $1995 .^{4}$ All have benefited from regular updates, the BTS collaborating with the Scottish Intercollegiate Guideline Network (SIGN) since 2003, most recently in 2016..$^{5}$ Each new iteration of the asthma guidelines was written by experts in the field and based on best available evidence. It is not known whether these guidelines (or any others) have improved the care of people with asthma; asthma prevalence has continued to rise (although it may now have plateaued), and deaths overall have not fallen, although this statistic is driven entirely by an ageing population, as deaths in England from asthma in the young have in fact dropped dramatically. ${ }^{6}$ It is likely, however, that guidelines have reduced variation in diagnosis and treatment of this complex disease.

In 2013, the National Institute for Health and Clinical Excellence (NICE) joined the guideline party, with a new approach that included consideration of health economics as well as clinical effectiveness. Their rationale included concerns that deaths were not falling, drug costs were rising and over-diagnosis and under-diagnosis still a significant issue. While the strength of evidence for each of these points varies (drug costs are rising across all areas of medicine, and over-diagnosis rates of $30 \%$ have been demonstrated repeatedly, even in recently diagnosed individuals ${ }^{7}$ ), all healthcare

Division of Infection, Immunity and Respiratory Medicine, School of Biological Sciences, The University of Manchester and Manchester University NHS Foundation Trust, Manchester, UK

${ }^{2}$ Firestone Institute of Respiratory Health, Department of Medicine, Michael G DeGroote School of Medicine, McMaster University, Hamilton, Ontario, Canada ${ }^{3}$ Pulmonary Department, Mainz University Hospital, Mainz, Germany

${ }^{4}$ Respiratory Research Unit, University of Nottingham, Nottingham, UK

Correspondence to Dr Stephen J Fowler, Education and Research Centre, Wythenshawe Hospital, Manchester M23 9LT, UK;

stephen.fowler@manchester.ac.uk professionals involved in the care of people with asthma would recognise that each of these issues do need careful consideration. However, what had not been established was whether these failures were due to the inadequacy of existing guidelines. If this were the hypothesis, then surely the rational approach would be to test current guidelines against a new proposed standard before development of the NICE guidelines? This has not happened; NICE have now published their guidance, ${ }^{8}$ after three consultation periods and a feasibility study, and people with asthma and the healthcare community have no idea whether the new guidance performs better or is easier to implement than the BTS/SIGN version. This would not be important if the general messages in the NICE guidance were similar to those already proposed. They are not. Recently, White and colleagues (in Thorax), ${ }^{9}$ the Primary Care Respiratory Society ${ }^{10}$ and many others ${ }^{11} 12$ have pointed out they give advice that is diametrically opposed to the BTS/SIGN guidance in many key areas.

For diagnosis, NICE insist that clinical history must be supported by objective testing, whereas BTS/SIGN support the clinical judgement of the doctor. In this, NICE are much more closely aligned to GINA, with the BTS/SIGN out of step with most national and international guidelines. Asthma is a disease defined by characteristic physiology, and as we know that the link between variable airflow obstruction and symptoms is minimal, relying on the diagnostic power of The Physician in isolation seems a curious approach. While we agree strongly that the diagnosis must be supported by objective testing, we find it harder to justify the emphasis NICE have placed on the measurement of exhaled nitric oxide (FeNO) in the diagnostic algorithm, with a proposed flat cut-off of $40 \mathrm{ppb}$ (35 ppb for children); data from healthy (non-asthmatic) volunteers in Sweden suggest that the upper limit of normal (ULN) ranges from $30 \mathrm{ppb}$ for a 30-year-old woman to $51 \mathrm{ppb}$ for a 65 -year-old man, with further adjustments required for atopy (atopic individuals having an ULN about $13 \mathrm{ppb}$ higher than non-atopic) and smoking (current smokers ULN about
5 ppb lower than non-smokers). ${ }^{13}$ The consequences of relying on an unadjusted cut-off in an untested algorithm are of course, unknown.

The BTS/SIGN diagnostic algorithm likewise does not make complete sense; the only route to a diagnosis of asthma, regardless of whether there was a high or intermediate clinical probability (in the opinion of The Physician), is via a positive response (which can be determined entirely on the basis of symptoms) to steroids. The potential for false negatives (through insensitive markers of response or through lack of adherence) and false positives (through placebo effect or natural variation in symptoms) is not considered, nor is the fact that not all asthma is responsive to low-dose inhaled corticosteroids, and not all steroid-responsive airway disease is asthma.

The truth probably lies somewhere between. Asthma is a clinical diagnosis, triggered by typical symptoms and supported by the demonstration of a variable and (partially) reversible airflow obstruction. However, the measurement of lung function and airway responsiveness in primary care is difficult, and FeNO is not useful for ruling in or ruling out a diagnosis of asthma. The determination of steroid responsiveness (along with other disease characteristics, treatable traits or phenotypes) should follow from that.

More contrasting guidance is given for management. NICE recommend that inhaled bronchodilators alone should be used first line, ignoring their own insistence that asthma diagnosis should be supported by evidence of airway inflammation and steroid responsiveness, via a raised $\mathrm{FeNO}$ - a true paradox. ${ }^{14} \mathrm{BTS} /$ SIGN have recently moved to recommending inhaled corticosteroids (ICS) as first line, possibly guided by the realisation that in many asthma deaths, over-reliance on short-acting bronchodilators and underuse of ICS play a significant role. ${ }^{1516}$ In the absence of good evidence to support either, the expert advisors on the committees (some of whom sat on both) have come to opposite conclusions.

The biggest controversy surrounds initial add-on therapy. NICE have recommended montelukast rather than addition of a long-acting beta- 2 agonist (LABA), on the basis of significantly reduced cost, offset by a relatively small reduction in mean benefit. The implications of this change in a clinical environment, where combination ICS/LABA therapy has been the mainstay of management steps 3-5 for 15 years, have not 
been considered. An important benefit of ICS/LABA therapy over montelukast is the reduction of the risk of severe asthma exacerbations. Adherence to tablets for asthma may well be greater than for inhalers, so does this mean that patients may preferentially choose the tablet over the inhaled steroid? What is the likelihood that patients will take two different drugs that have no immediate efficacy feedback? Finally, two prescription fees will be paid by many, in contrast to those prescribed fixed ICS/LABA combinations.

Lastly, while both guidelines cover diagnosis and chronic disease pharmacotherapy, BTS/SIGN (like GINA) are far more comprehensive and include guidance on acute asthma, asthma in pregnancy and transitional care, among many other aspects.

NICE acknowledge the practical impossibility of fully implementing their guidance at this time: "...primary care services should implement what they can of the recommendations, using currently available approaches to diagnosis until the infrastructure for objective testing is in place", which makes us wonder why they have persevered with publishing them, rather than focusing their efforts on providing evidence to support this infrastructure. Although we recognise and support the need to scrutinise and renew guidelines regularly in the light of new evidence, having two sets of guidelines will only lead to confusion, worse outcomes and potentially higher cost.

Asthma management is already complicated and there are now more treatment options than ever before. What is required is not varying and contradictory guidance, but testing of both the evidence for and implementation of current guidelines, before changes can be recommended, in a joint effort that would catapult the UK to the global forefront of asthma healthcare research. Why BTS/SIGN and NICE have not decided that the best way forward for people with this life-threatening chronic disease is to work together (imagine the uproar if we had two sets of UK resuscitation guidelines) is unclear. This is must happen, and quickly, in the interests of patient safety.

Contributors SJF wrote the first draft of the manuscript based on discussions between all authors. $P M O O^{\prime} B, R B$ and DS reviewed and revised this draft. All authors approved the final submitted manuscript.

Funding The authors have not declared a specific grant for this research from any funding agency in the public, commercial or not-for-profit sectors.

Competing interests In the last three years: SJF reports personal fees from AstraZeneca, Boehringer Ingelheim, GlaxoSmithKline, and Novartis, and investigator-initiated research funding from Boehringer Ingelheim; PMO'B has held grants-in-aid from AstraZeneca, Medimmune, Novartis, and received consulting fees from AstraZeneca, GSK, and Boehringer; RB reports personal fees from AstraZeneca, Boehringer Ingelheim, Chiesi, Cipla, Novartis, Roche, and Teva, grants to Mainz University from Boehringer Ingelheim, GlaxoSmithKline, Novartis, and Roche, he is chair of the German asthma guideline committee since 2006 and a member of the science committee of the Global Initiative for Asthma (GINA) since 2016; DS reports personal fees from AstraZeneca, Boehringer Ingelheim , Novartis and Teva, and grants from GlaxoSmithKline.

Patient consent Not required.

Provenance and peer review Not commissioned; externally peer reviewed.

(C) Article author(s) (or their employer(s) unless otherwise stated in the text of the article) 2018. All rights reserved. No commercial use is permitted unless otherwise expressly granted.

\section{A) Check for updates}

To cite Fowler SJ, O'Byrne PM, Buhl R, et al. Thorax 2018;73:797-798.

Accepted 16 April 2018

Published Online First 3 May 2018

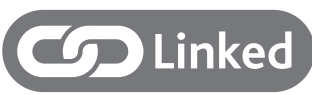

- http://dx.doi.org/10.1136/thoraxjnl-2017-211189

Thorax 2018;73:797-798.

doi:10.1136/thoraxjn-2018-211703

\section{REFERENCES}

1 Woolcock A, Rubinfeld AR, Seale JP, et al. Thoracic Society of Australia and New Zealand. Asthma management plan, 1989. Med J Aust 1989:151:650-3.
2 Guidelines for management of asthma in adults: Ichronic persistent asthma. Statement by the British Thoracic Society, Research Unit of the Royal College of Physicians of London, King's Fund Centre, National Asthma Campaign. BMJ 1990;301:651-3.

3 Guidelines for the diagnosis and management of asthma. National Heart, Lung, and Blood Institute. National Asthma Education Program. Expert Panel Report. J Allergy Clin Immunol 1991;88(3 Pt 2):425-534.

4 National Heart L, and Blood Institute and World Health Organization. Global strategy for asthma management and prevention. WHO/NHLB/workshop report: Bethesda (MD), 1995.

5 Society BT, Network SIG. British guideline on the management of asthma 2016. https://www.britthoracic.org.uk/document-library/clinical-information/ asthma/btssign-asthma-guideline-2016/ (accessed 16 Feb 2018).

6 Statistics OfN. Asthma deaths in England and Wales, 2001 to 2015 occurrences: Office for National Statistics. 2016 https://www.ons.gov.uk/peoplepopula tionandcommunity/birthsdeathsandmarriages/deaths/ adhocs/005955asthmadeathsinenglandandwales2 001to2015occurrences (accessed 16 Feb 2018).

7 Aaron SD, Vandemheen KL, FitzGerald JM, et al. Reevaluation of diagnosis in adults with physiciandiagnosed asthma. JAMA 2017;317:269-79.

8 Excellence NIfHaC. Asthma: diagnosis, monitoring and chronic asthma management 2017. https://www.nice. org.uk/guidance/ng80 (accessed 16 Feb 2018).

9 White J, Paton JY, Niven R, et al. Guidelines for the diagnosis and management of asthma: a look at the key differences between BTS/SIGN and NICE. Thorax 2018:73:293-7.

10 Keeley D, Baxter N. Conflicting asthma guidelines cause confusion in primary care. BMJ 2018;360:k29.

11 Copperfield. What breathtakingly useless guidance: pulse. 2017 http://www.pulsetoday.co.uk/views/ copperfield-/what-breathtakingly-useless-guidance/ 20035751.article (accessed 16 Feb 2018).

12 Shaw D, Fowler SJ, Walker S. Asthma guidelinessame questions, different answers BMJ Opinion: BMJ. 2017 https://blogs.bmj.com/bmj/2017/04/12/ asthma-guidelines-same-questions-different-answers/ (accessed 16 Feb 2018).

13 Torén K, Murgia N, Schiöler L, et al. Reference values of fractional excretion of exhaled nitric oxide among non-smokers and current smokers. BMC Pulm Med 2017:17:118.

14 O'Byrne PM, Jenkins C, Bateman ED. The paradoxes of asthma management: time for a new approach? Eur Respir / 2017:50:1701103.

15 Physicians RCo. Why asthma still kills: the National Review of Asthma Deaths (NRAD) Confidential Enquiry Report: RCP. 2014 www.rcplondon.ac.uk/sites/default/ files/why-asthma-still-kills-full-report.pdf

16 Reddel HK, Busse WW, Pedersen S, et al. Should recommendations about starting inhaled corticosteroid treatment for mild asthma be based on symptom frequency: a post-hoc efficacy analysis of the START study. Lancet 2017;389:157-66. 